\title{
Microfacies, Diagenesis and Reservoir Quality of Early Triassic Kangan Formation in Offshore Zagros: A Case Study
}

\author{
Farkhondeh Kiani Harchegani (Azad University of Khorasgan, Iran \\ $<$ bitaa1979@yahoo.com>), Mohammd Reza Kamali (Research Institute of Petroleum \\ Industry (RIPI)) and Behrooz Esrafili Dizaji (University of Tehran, MAPSA Co.)
}

\begin{abstract}
Significant amounts of hydrocarbon resources are hosted by the Lower Triassic Kangan Formation (Upper Khuff equivalent) in the southern part of Gulf. This carbonate gas reservoir is known to be a complex carbonate system with a high degree of heterogeneity, which has a direct impact on the reservoir quality. The formation consists mainly of limestone, dolomitic limestone, dolomite and evaporites. Combined core examinations and detailed thin section studies are used for facies analysis. Accordingly, 10 major facies were recognized in the Kangan reservoir. They are grouped as five facies assemblages deposited in supratidal, intertidal, lagoon, shoal and off-shoal environments. These facies associations reflect an ideal shallowing upward sequence. These facies are genetically related and indicate a gentle depositional gradient and morphology during deposition. Thus, they represent the shallow part of a homoclinal carbonate ramp (Figure 1). This interpretation is based on the characteristics of the constituent facies, lateral and vertical relations between sedimentary facies and the presence of thick succession of shallow-water deposits (high relative proportion of peritidal and lagoon versus open-marine facies).
\end{abstract}

Reservoir properties are greatly affected by diagenetic events such as dolomitization, cementation, micritization, compaction and dissolution. Cementation is the main diagenetic process that reduces reservoir quality, by occluding pore spaces in some parts. Cathodoluminescence petrography revealed the following three calcite cement types, which are generated during early to burial diagenesis:

(1) non-ferroan fibrous cement consists of thin fibrous fringes (10-15 um) and exhibits light brown luminescence. This cement was formed in eogenetic diagenetic stages under influence of marine condition.

(2) Ferroan bladed calcite cement that exhibits bladed texture with about 30-70 um long. It is non-luminescent and formed in eogenetic diagenetic stages with possible origin of meteoric and mixing-zone waters.

(3) Ferroan blocky calcite cement which is characterized by coarse crystalline (200-350 um) texture, displaying a dull-dark luminescence (Figure 2). It was generated in burial diagenesis setting with no recharge of surface waters.

Three types of dolomitic cements are recognized in the Kangan reservoir in general. They include limpid dolomite, coarse inclusion rich dolomite and saddle dolomite. Limpid cements, probably formed in mixing-zone environments, are not common in reservoir rocks. The most abundant dolomite cements, coarse dolomitic ones are characterized by having several zones, under CL microscopic studies. These zones are: 1) ferroan, non-luminescent zone, 2) dark brown zone, 3) light brown to orange zone and 4) dull zone (Figure 3). Saddle dolomite cement is scarce, and formed in deep-burial diagenesis conditions. Therefore, paragenetic sequence reconstructed based on petrographic observations suggest that diagenetic carbonate cements have been formed in early, burial and deep- burial diagenesis stages which cause a significant reduction of porosity in the Kangan Formation (Figure 4). 
EAGE

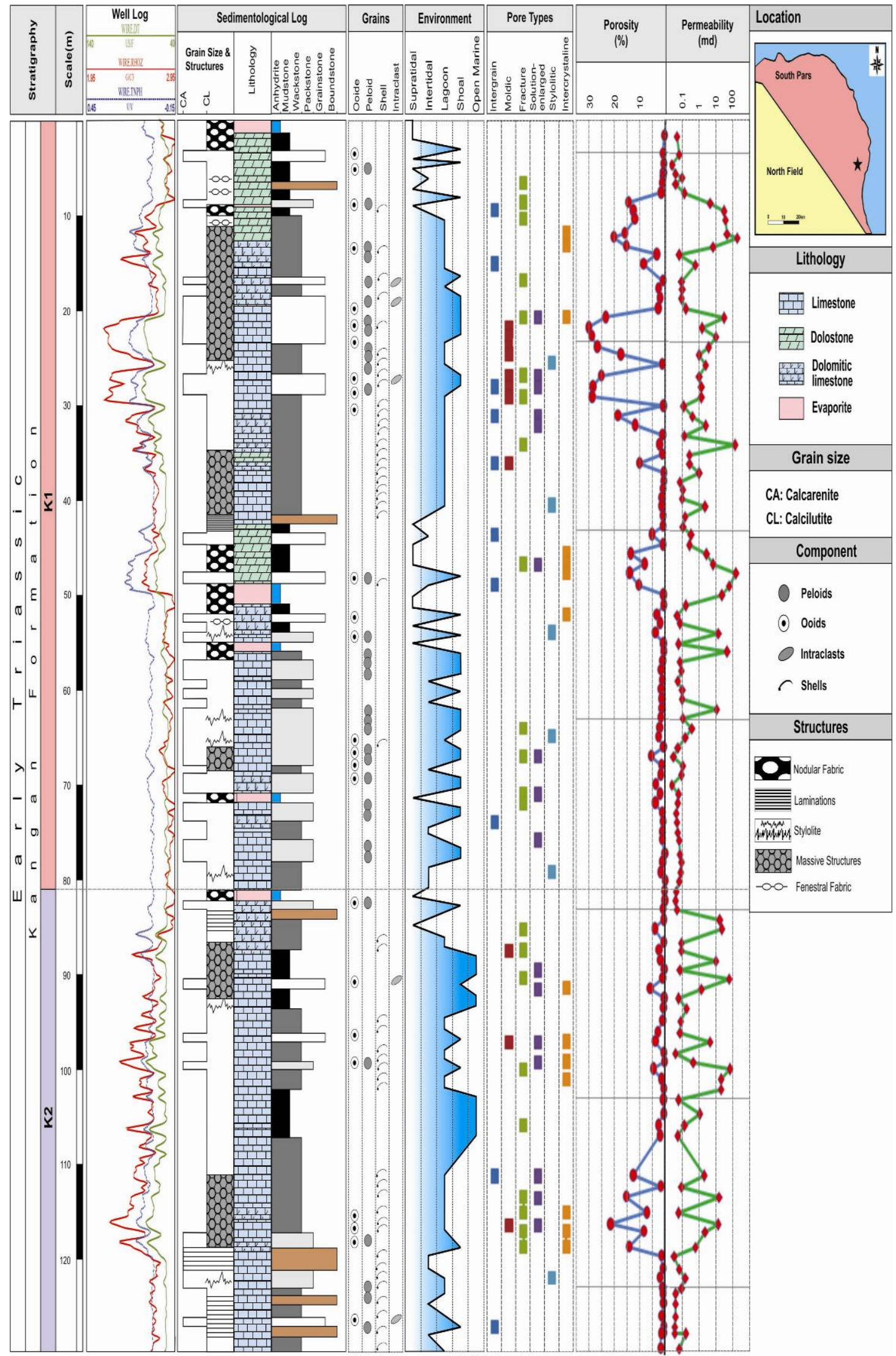

Figure 1: Sedimentological logs showing facies belts and poroperm values of Kangan Formation in Well A. 


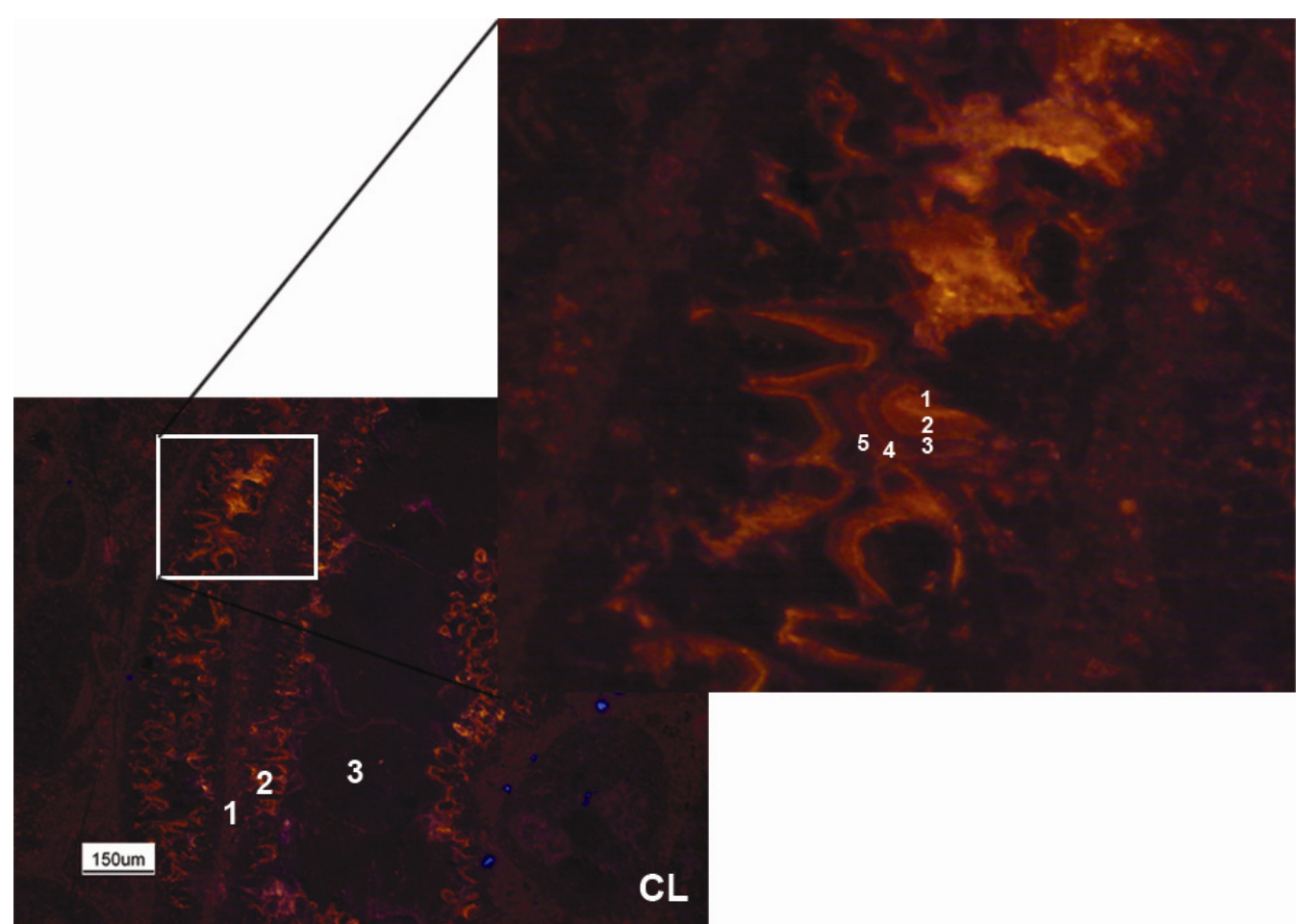

Figure 2: CL image of marine fibrous cements (1), meteoric bladed (2) and coarse burial bulky cements (3), zoomed picture shows zonation in calcite cements due to change of chemistry of diagenetic fluids.
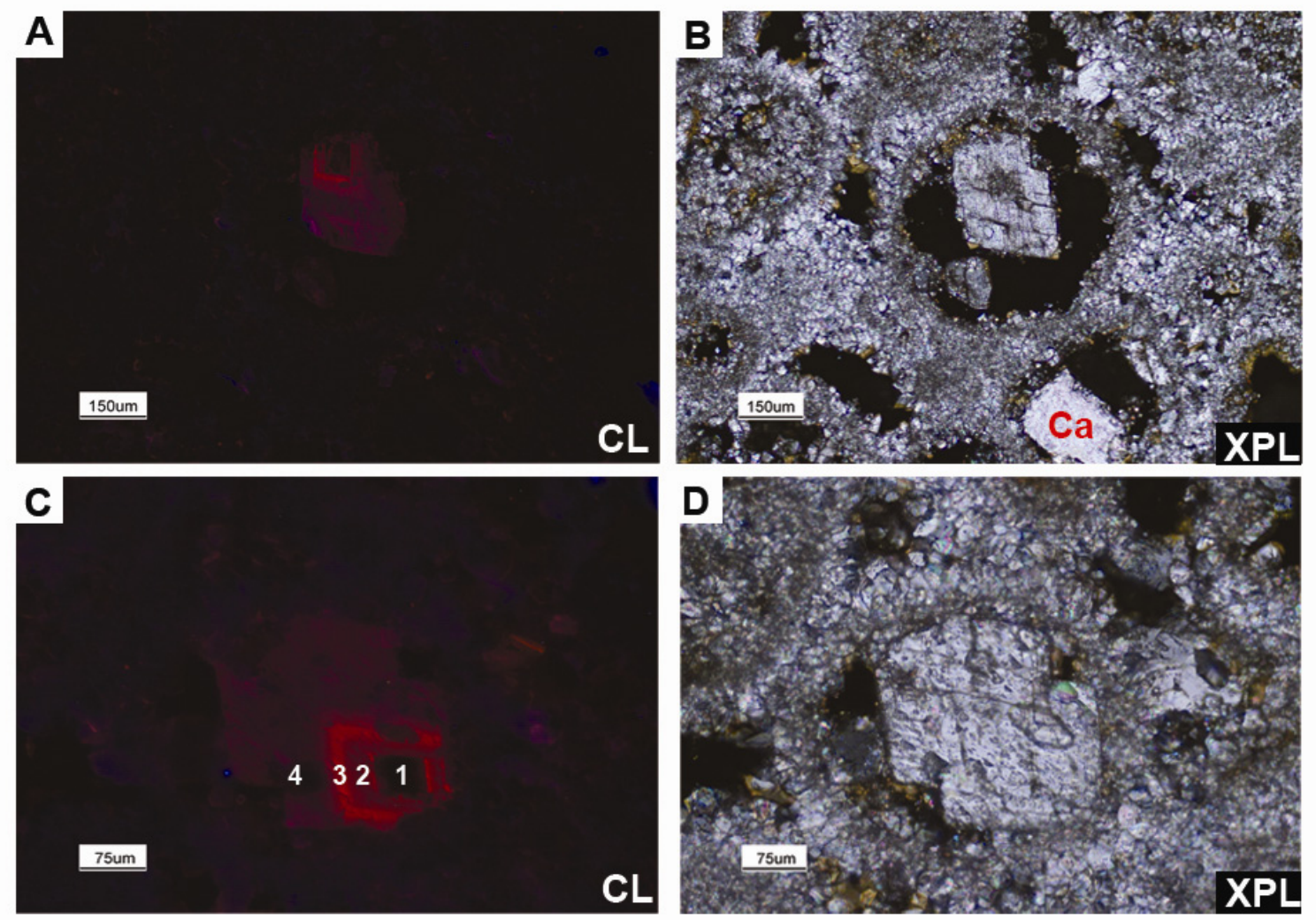

Figure 3: CL zonation of coarse inclusion rich dolomite cements occluding oomolds in shoal facies. 

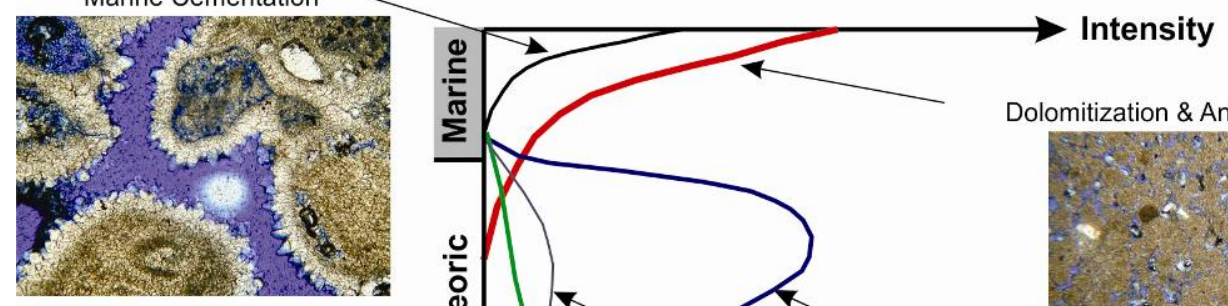

Neomorphism

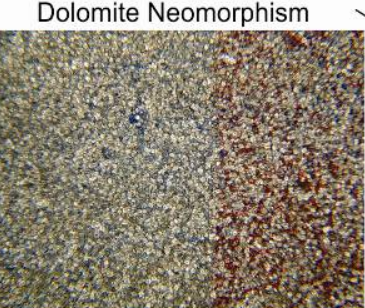

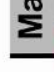
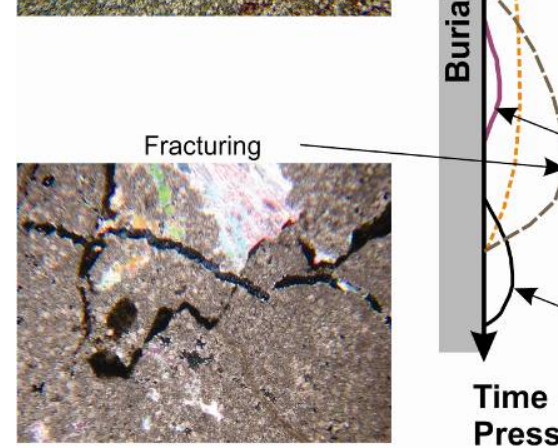

Pressure

Temeprature

Dolomitization \& Anhydrite Precipitation

Figure 4: Paragenetic sequence of Kangan Formation in well A. 